\title{
Age differences in moral judgment: Older adults are more deontological than younger adults
}

\author{
Simon McNair ${ }^{1}$ (D) | Yasmina Okan ${ }^{1}$ | Constantinos Hadjichristidis ${ }^{1,2}$ | \\ Wändi Bruine de Bruin ${ }^{1,3}$
}

${ }^{1}$ Centre for Decision Research, Leeds University Business School, Maurice Keyworth Building, University of Leeds, Leeds, UK

${ }^{2}$ Department of Management and Economics, University of Trento, Trento, Italy

${ }^{3}$ Department of Engineering and Public Policy, 129 Baker Hall, Carnegie Mellon University, Pittsburgh, PA, USA

\section{Correspondence}

Simon McNair, Centre for Decision Research, Leeds University Business School, Maurice Keyworth Building, University of Leeds, Moorland Road, Leeds LS2 9JT, UK.

Email: s.j.mcnair@leeds.ac.uk

Funding information

Leverhulme Early Career Fellowship, Grant/ Award Number: ECF-2015-067, McNair; European Union Seventh Framework Programme, Grant/Award Number: FP7-PEOPLE2013-CIG-618522, Bruine de Bruin

\begin{abstract}
In 2 studies, an older and a younger age group morally evaluated dilemmas contrasting a deontological judgment (do not harm others) against a utilitarian judgment (do what is best for the majority). Previous research suggests that deontological moral judgments are often underpinned by affective reactions and utilitarian moral judgments by deliberative thinking. Separately, research on the psychology of aging has shown that affect plays a more prominent role in the judgments and decision making of older (vs. younger) adults. Yet age remains a largely overlooked factor in moral judgment research. Here, we therefore investigated whether older adults would make more deontological judgments on the basis of experiencing different affective reactions to moral dilemmas as compared with younger adults. Results from 2 experiments indicated that older adults made significantly more deontological moral judgments. Mediation analyses revealed that the relationship between age and making more deontological moral judgments is partly explained by older adults exhibiting significantly more negative affective reactions and having more morally idealistic beliefs as compared with younger adults.
\end{abstract}

\section{KEYWORDS}

aging, emotion, individual differences, judgment and decision making, moral judgment

\section{1 | INTRODUCTION}

Moral decisions pervade public and professional life. Topics such as abortion, assisted suicide for the terminally ill, and the death penalty remain highly contentious and morally charged. Many studies have investigated people's moral choices in sacrificial scenarios, where human lives are at stake. A widely studied problem is Foot's (1967) trolley dilemma, a thought experiment in which five people are about to be killed by a runaway trolley unless action is taken. In the original version, the action involves pressing a switch to redirect the trolley onto a different track where only one person is standing. In an alternative version, the action involves pushing a person from a footbridge onto the tracks to stop the trolley (Thomson, 1985). Although these dilemmas may seem similar, most people agree to kill one to save five in the switch version but not in the footbridge version. That is, people give utilitarian judgments (do what is best for the majority) for the switch dilemma but deontological judgments (do not harm others) for the footbridge dilemma (e.g., Greene, Nystrom, Engell, Darley, \& Cohen, 2004; Hauser, Cushman, Young, Kang-Xing, \& Mikhail, 2007). This finding has been replicated for different types of moral dilemmas (e.g., Gold, Pulford, \& Colman, 2013). Theories have focused on the affective and cognitive processes underlying moral judgments (Cushman, Young, \& Hauser, 2006; Moore, Clark, \& Kane, 2008).

A limitation of research on moral judgments in footbridge- and switch-like dilemmas is that it typically recruited undergraduate students with mean ages below 30 years (e.g., Greene, Morelli, Lowenberg, Nystrom, \& Cohen, 2008; Lotto, Manfrinati, \& Sarlo, 2013; Suter \& Hertwig, 2011). Yet there is evidence of age differences in decision making, possibly resulting from age-related changes in affective and cognitive processing (Hess, Strough, \& Lockenhoff, 2015). Understanding age differences in moral judgment is important because older adults occupy some of the highest power positions that 
involve important moral judgments. For example, the average age of current G20 world leaders is 62.1 years and that of Fortune 100 CEOs 57 years (Myatt, 2013). The present study therefore aimed to examine whether older and younger adults diverge in their moral judgments and to uncover the mechanisms underlying any existing differences.

\section{2 | DELIBERATIVE AND AFFECTIVE PROCESSES IN MORAL JUDGMENT}

Utilitarian moral judgments, or choices to sacrifice one person to save a larger number of people, have typically been attributed to deliberative reasoning (Cushman et al., 2006; Greene et al., 2004; Greene, Sommerville, Nystrom, Darley, \& Cohen, 2001; Moore et al., 2008). Indeed, factors that hinder people's ability to deliberate, such as time pressure and cognitive load, generally suppress utilitarian judgments (Greene et al., 2008; Suter \& Hertwig, 2011). Additionally, utilitarian judgments are more likely when emotional reactivity is reduced. For instance, utilitarian judgments are more common among individuals with damage in brain regions involved in emotional responsivity (Koenigs et al., 2007), those with lower degrees of trait empathy (i.e., the ability to actively consider other's emotional perspectives; Choe \& Min, 2011; Conway \& Gawronski, 2013) and those with higher degrees of sub-clinical psychopathy, which is characterized by having no empathy for others (Kahane, Everett, Earp, Farias, \& Savulescu, 2015). Presumably, dampened affect yields less cognitive-affective conflict about intervening (Koenigs, Kruepke, Zeier, \& Newman, 2011). Evidence suggests, then, that utilitarian moral judgments are more likely when deliberation is engaged, or when emotional reactivity is reduced.

In contrast, deontological moral judgments are often associated with relatively elevated affective reactions. For instance, people report higher levels of negative affect when facing trolley-type dilemmas and are more likely to choose to not intervene, thus avoiding to kill anyone to save others (Lotto et al., 2013). Moreover, brain imaging studies have found that increased activation in brain areas associated with negative affective states is related to more deontological judgments (e.g., Greene et al., 2001, 2004). Recent research has begun to shed further light on such effects, determining a key role for emotional valence (whether the emotional experience is positive or negative), as opposed to emotional arousal (the magnitude of emotional activation). For example, negatively valenced affect leads students to condemn moral transgressions (e.g., eating your dead dog), independent of arousal (de la Vi a, Garcia-Burgos, Okan, Cándido, \& González, 2015). Instead, positive affect can increase utilitarian responses to moral dilemmas such as the footbridge dilemma (Valdesolo \& DeSteno, 2006). Taken together, these findings suggest that affective reactions with the same level of arousal may affect moral judgments differently depending on their valence. Specifically, deontological moral judgements may be more likely among individuals who rely more on affective rather than deliberative processing-but only if they experience more negative emotions. Distinguishing these emotional mechanisms is particularly relevant in the context of aging, as there is evidence suggesting that younger and older adults differ with respect to how arousal (e.g., Kensinger, 2008) and valence (e.g., Leigland, Schulz, \& Janowsky, 2004) influence affective processing.

\section{I AGE DIFFERENCES IN AFFECTIVE AND DELIBERATIVE PROCESSING}

Research on judgment and decision making across the lifespan has indicated age-related shifts in the relative influence of affective and deliberative processes (Hess et al., 2015; Peters \& Bruine de Bruin, 2012). Older age has been associated with declines in deliberative abilities such as working memory (Reuter-Lorenz \& Sylvester, 2005; Verhaeghen, Marcoen, \& Goossens, 1993), executive functioning (Amieva, Phillips, \& Della Sala, 2003), and processing speed (Salthouse, 2004). Although deliberative abilities tend to decline with age, affective processing may improve (Mikels, Larkin, Reuter-Lorenz, \& Carstensen, 2005). According to research on the affect heuristic, decisions may rely more on affect particularly when deliberation becomes difficult, or affective reactions are strong (Slovic, Finucane, Peters, \& MacGregor, 2002). Perhaps as a result, emotional cues are more likely to be noticed and remembered by older adults (Carstensen \& Turk-Charles, 1994; Fung \& Carstensen, 2003). As compared with younger adults, older adults can also find it difficult to resist the effect of affective cues on judgments (Hess, Waters, \& Bolstad, 2000). Further, although there is contrasting evidence concerning age differences in performance on risky decisions for the lowa gambling task (Kovalchik, Camerer, Grether, Plott, \& Allman, 2005; Mata, Josef, Samanez-Larkin, \& Hertwig, 2011), it has been observed that older adults rely more on emotional cues for this task, whereas younger adults' performance is contingent on their deliberative skills (Wood, Busemeyer, Koling, Cox, \& Davis, 2005).

Additionally, socioemotional selectivity theory (Carstensen, 2006) posits that older adults become especially motivated to maximize their positive emotional experiences, so as to make the best of the limited time they perceive to have left. Older adults may therefore be more likely to seek and remember positive than negative information (Mather \& Carstensen, 2005). This so-called positivity effect plays a role in a wide range of older adults' decisions (Carstensen \& Mikels, 2005; Mather \& Carstensen, 2005). Older age has also been associated with less neural reactivity to negative stimuli (Wood \& Kisley, 2006) and less negative affect in the face of adverse experiences (Bruine de Bruin, van Putten, van Emden, \& Strough, In press). Older adults tend to be better than younger adults at avoiding preoccupation with negative thoughts about adverse events, which helps them to maintain better overall emotional well-being (Kessler \& Staudinger, 2009; Torges, Stewart, \& Nolen-Hoeksema, 2008). As a result, older age is potentially associated with experiencing less negative affect, perhaps especially when experiencing adverse outcomes (Bruine de Bruin et al., In press; Mikels et al., 2005).

\section{4 | RESEARCH QUESTIONS}

Taken together, the findings reviewed suggest two potential mechanisms underlying age-related differences in moral judgments. On the one hand, older adults' increased reliance on affect rather than deliberation could lead to more deontological moral judgments. On the 
other hand, older adults tend to experience less negative affect, which could instead result in less deontological judgments. As noted above, reduced negative affect is associated with making less deontological moral judgments (Greene et al., 2001, 2004). Here, we aimed to shed light on age-related differences in moral judgments and the underlying role of emotions. Across two experiments, we presented older and younger participants with validated moral dilemmas. We asked for two moral judgments (following Lotto et al., 2013): whether they would intervene to save a larger group of people at the expense of one or two individuals and how morally acceptable they perceived the intervention to be. In both experiments, we also assessed participants' emotional reactions, including valence and arousal (following de la Vi a et al., 2015, and Lotto et al., 2013). In Experiment 2, we also assessed individual differences potentially relevant to age differences in moral judgment.

Specifically, our research questions were as follows:

1. Do older and younger adults differ in their propensity toward deontological versus utilitarian moral judgements?

2. Do older and younger adults differ in their affective reactions when making moral judgments?

3. Are any age differences in moral judgments mediated by age differences in affective reactions?

In both experiments, we also controlled for sociodemographic factors, given previous findings concerning differences in moral judgments contingent upon gender (see Walker, 2014), ethnicity (Carlos, Alsua, \& Carneiro, 2012), education level (e.g., Pratt, Diessner, Pratt, Hunsberger, \& Pancer, 1996), and political orientation (e.g., Piazza \& Sousa, 2014)

\section{5 | EXPERIMENT 1}

In Experiment 1, we presented older and younger participants with 26 moral dilemmas where peoples' lives were at stake, taken from Lotto et al. (2013). Half of the dilemmas entailed an "instrumental" intervention (i.e., the proposed intervention would cause the death of one or two people as an intended means to save a larger number of people), whereas the other half entailed "incidental" interventions (i.e., the proposed intervention would cause their death as a foreseen but unintended consequence). Furthermore, half referred to other people as beneficiaries of the intervention ("other" dilemmas), and half also benefited oneself ("self" dilemmas). Moral judgments and affective reactions can vary across these instrumental versus incidental and self versus other dimensions (Lotto et al., 2013; Moore et al., 2008). Including dilemmas that varied along those two dimensions allowed us to examine whether eventual age-related effects depend on dilemma type.

\section{6 | METHOD}

\section{1 | Participants}

Participants were 150 middle-aged and older adults (55-81 years, $\left.M_{\text {age }}=62, S D=5.7\right)$ and 152 emerging younger adults (18-25 years,
$M_{\text {age }}=22.4, S D=1.9$ ), recruited from U.S. residents using Amazon's Mechanical Turk. They had been screened in an initial questionnaire that tested whether they met our age criteria. Although both age groups have been characterized in the literature, life-span developmental processes are typically thought of as continuous rather than limited to discrete age ranges (Arnett, 2007; Baltes \& Smith, 2003; Lachman, 2004). Yet extreme age group designs are commonly used to increase statistical power (e.g., Isaacowitz, Toner, Goren, \& Wilson, 2008; Strough, Mehta, McFall, \& Schuller, 2008). For brevity, we will henceforth refer to the first age group as "younger" and the second age group as "older" (following Isaacowitz et al., 2008; Strough et al., 2008).

The older group comprised $63 \%$ females, $55 \%$ with University degrees and $10 \%$ non-Whites. The younger group comprised $64 \%$ females, $41 \%$ with University degrees and 20\% non-Whites. Chisquare tests indicated significant age group differences in having a University degree, $\chi^{2}(1, N=302)=5.27, p=.032$, and ethnic group, $\chi^{2}(1, N=302)=5.65, p=.042$. A chi-square test indicated that age group was also marginally-significantly associated with political attitude (left, center, and right): $\chi^{2}(2, N=302)=5.19, p=.08$. Post-hoc tests indicated a significant difference in the number of older adults ( $N=55$ ) identifying as political right-leaning compared with younger adults $(N=35): t(300)=2.00, p=.038$. All analyses for Experiment 1 included dummy variables to control for these sociodemographic factors (university degree: 0 = no, 1 = yes; ethnic group: $0=$ nonWhite, 1 = White; politically right: $0=$ no, $1=$ yes.) Participants received \$1 for completing the experiment. Those who did not meet the age criteria (i.e., were neither 18-25 nor 55+ years old) were thanked and received \$.05.

\section{2 | Materials}

\subsection{1 | Moral dilemmas}

Participants viewed 26 scenarios, including 2 versions of the classic trolley scenarios (Foot, 1967; Thomson, 1985) and 24 taken from Lotto et al. (2013). Each scenario described a hypothetical situation in which a number of people would die unless an intervention resulted in the death of one or two people. Scenarios were selected according to two criteria. First, we selected an equal number of scenarios from Lotto et al.'s (2013) four categories, which crossed instrumental versus incidental intervention types with self versus other involvement (Table 1). Second, within each category, we selected six scenarios that yielded good variability in the number of accepted interventions (as reported by Lotto et al., 2013). We avoided scenarios for which interventions were accepted or rejected by most participants (following Suter \& Hertwig, 2011). Full texts for all scenarios and accompanying introductions are presented in Supporting Information. The order of presentation of scenarios was randomized across participants.

\subsection{2 | Moral judgments}

After each scenario, participants answered two moral judgment questions taken from Lotto et al. (2013). The first asked "Would you perform the stated action (yes/no)." For each of the incidental/instrumental $\times$ self/other dilemma types, we computed the total number of 
TABLE 1 Examples of moral dilemma scenarios used in Experiment 1

\begin{tabular}{|c|c|c|}
\hline Category & Moral dilemma scenario & Proposed intervention \\
\hline $\begin{array}{l}\text { Incidental, } \\
\text { Self }\end{array}$ & $\begin{array}{l}\text { You are a fireman trying to save five people from inside a } \\
\text { burning building. The only window from which the people } \\
\text { can be evacuated is jammed and will not open. The fire } \\
\text { will reach you in a short time. Outside on the window ledge } \\
\text { of the floor below, there is a person who is waiting to } \\
\text { be saved. }\end{array}$ & $\begin{array}{l}\text { With an axe, you smash the window to get out. You know } \\
\text { that when it falls, the heavy glass will kill the person on } \\
\text { the lower floor, but you and the five people in danger } \\
\text { will be able to escape. }\end{array}$ \\
\hline $\begin{array}{l}\text { Instrumental, } \\
\text { Self }\end{array}$ & $\begin{array}{l}\text { You are travelling in the middle-east. You and another } \\
\text { six tourists are taken hostage by a group of terrorists. } \\
\text { The terrorists think that one of you is a spy, even though } \\
\text { this is not true. You are held hostage for days. One of } \\
\text { the terrorists comes to you and reveals that they intend to } \\
\text { kill you all at sunset. }\end{array}$ & $\begin{array}{l}\text { While he is resting, you kill one of the tourists in the group } \\
\text { so that you can tell the terrorists that you identified and } \\
\text { eliminated the spy. The person will die, but you and the } \\
\text { other five will be freed. }\end{array}$ \\
\hline $\begin{array}{c}\text { Incidental, } \\
\text { Other }\end{array}$ & $\begin{array}{l}\text { You are a nurse who is in charge of a machine that controls } \\
\text { drug dosage levels in patients' blood. Because of a } \\
\text { technical failure, the machine is supplying a lethal dose } \\
\text { of a drug to four patients. Another patient, in a single } \\
\text { room, is hooked up to the same machine and has not } \\
\text { undergone any variation in dosage. }\end{array}$ & $\begin{array}{l}\text { You press the button to block the drug supply to the four } \\
\text { patients. You know that the overdose of drug will be } \\
\text { redirected to the patient in the single room, who will } \\
\text { die, but the other four will be saved. }\end{array}$ \\
\hline $\begin{array}{l}\text { Instrumental, } \\
\text { Other }\end{array}$ & $\begin{array}{l}\text { You are the head zoo keeper and you are doing the rounds } \\
\text { with another keeper. You realize that one of the cleaners } \\
\text { has left the lions' cage open by mistake. You see that a } \\
\text { lion is coming toward the open gate and you do not have } \\
\text { time to close it. There are three visitors right in front } \\
\text { of the gate. }\end{array}$ & $\begin{array}{l}\text { You push the keeper next to you against the gate to stop } \\
\text { the lion from getting out. You know that the man will } \\
\text { be attacked and killed, but the three visitors will be saved. }\end{array}$ \\
\hline
\end{tabular}

scenarios for which respondents chose to intervene. Totals were out of six for incidental-self and instrumental-self dilemmas (Cronbach's $a=.83$ and .81 , respectively) and out of seven for both incidental-other and instrumental-other dilemmas (Cronbach's $\alpha=.81$ and .80 , respectively) on account of the additional trolley dilemmas, both other. The second question asked "How morally acceptable did you find the proposed action?" followed by a scale from 1 (not at all acceptable) to 7 (totally acceptable). For each of the four dilemma types, we computed the average rating. Cronbach's a for each type of dilemma ranged from .89 to .92 . For both measures, higher scores reflected more utilitarian and less deontological moral judgments.

\subsection{3 | Affect}

Participants indicated their affective valence and arousal, by respectively rating how "calm or agitated" and how "unpleasant or pleasant" they felt "when deciding whether or not to do the proposed action in the scenario you just read?" (following Lotto et al., 2013). Ratings were given on a pictorial scale of nine figures transitioning along the relevant affective dimension (following Bradley \& Lang, 1994; Figure 1). For each of the four dilemma types, we computed average arousal and valence ratings, as analyses indicated high internal consistency (for all, Cronbach's $a \geq .88$ ). Scores on both affective measures ranged from 1 to 9, with higher scores representing more positively valenced reactions and higher emotional arousal.

\section{3 | Procedure}

After reading each moral dilemma, participants clicked a button when ready. The proposed intervention was presented on a separate screen, where participants indicated whether or not they would perform the action (yes/no). A subsequent screen asked how morally acceptable the action was, followed by valence and arousal ratings. No time limits were imposed on participants.

\section{7 | RESULTS}

\section{1 | Analysis plan}

We conducted 2 (older vs. younger age group) $\times 2$ (instrumental vs. incidental intervention type) $\times 2$ (self vs. other risk involvement) analyses of covariance (ANCOVAs) for each of the four dependent variables, controlling for sociodemographic differences (education, ethnicity, and political right). To answer Research Question 1, we

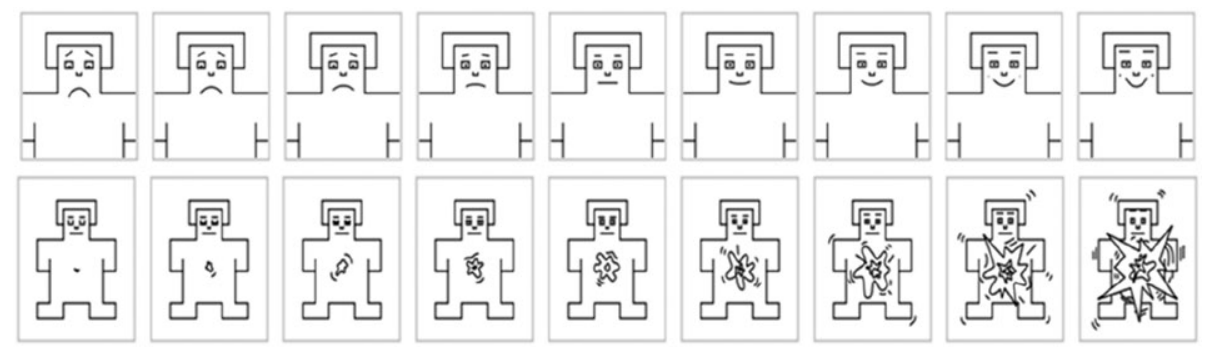

FIGURE 1 Self-assessment manikin (Bradley \& Lang, 1994) 
examined ANCOVAs for the two moral judgment measures. To answer Research Question 2, we examined ANCOVAs for the two affect measures. To answer Research Question 3, we performed mediational analyses that examined whether any relationships between age group and moral judgment measures could be statistically explained by affect measures.

\subsection{Do older and younger adults differ in their propensity toward deontological versus utilitarian moral judgments?}

\subsection{1 | Accepted interventions}

A main effect of age group for total accepted interventions indicated that older adults accepted significantly fewer interventions: $F(1$, $297)=18.73, p<.001, \eta_{p}{ }^{2}=.06$ (Table 2). There was a significant main effect of intervention type, $F(1,297)=12.95, p<.001$, with fewer instrumental than incidental interventions accepted $(M=5.07$, $S D=4.09$ vs. $M=7.36, S D=4.11$, respectively). All remaining tests yielded $F<2.20, p>.14$ (Table $S 2$ ).

\subsection{2 | Moral acceptability judgments}

A significant main effect of age group emerged, $F(1,297)=14.12$, $p<.001, \eta_{\mathrm{p}}{ }^{2}=.05$, whereby older adults rated interventions as less morally acceptable (Table 2). A main effect of intervention type, $F(1$, $297)=16.52, p<.001, \eta_{p}{ }^{2}=.05$, showed lower acceptability ratings for instrumental $(M=2.77, S D=1.45)$ compared with incidental interventions $(M=3.22, S D=1.48)$. All remaining tests yielded $F<1.95$, $p>.16$ (Table S2).

\section{3 | Do older and younger adults differ in their affective reactions when making moral judgments?}

\subsection{1 | Valence}

A main effect of age group emerged: $F(1,297)=13.11, p<.001$, $\eta_{\mathrm{p}}{ }^{2}=.04$ with older adults giving lower ratings (indicating more negative affect), as compared with younger adults (Table 2). All remaining tests yielded $F<1.69, p>.19$ (Table S3).

\subsection{2 | Arousal}

There was a marginal age group $\times$ risk involvement interaction for arousal: $F(1,297)=3.69, p=.054, \eta_{p}{ }^{2}=.02$. Specifically, moral dilemmas were rated as more arousing when the beneficiary included the self, rather than only others. Differences linked to risk involvement, however, were small both among younger (Cohen's $d=.15$ ) and older adults (Cohen's $d=.08) .{ }^{1}$ All remaining tests yielded $F<.60, p>.44$ (Table S3).

\section{4 | Are any age differences in moral judgments mediated by age differences in affective reactions?}

Mediational analyses collapsed across instrumental versus incidental intervention type and self versus other involvement, because we

${ }^{1}$ Reported Cohen's $d$ effect sizes accounted for dependence between variables.

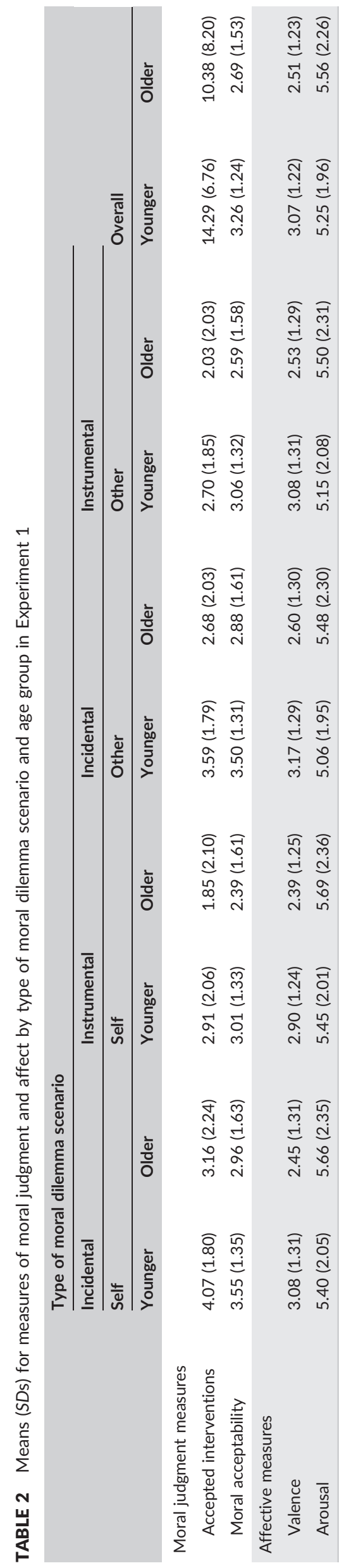


TABLE 3 Partial correlations between measures of moral judgment and affect in Experiment 1

$\begin{array}{lllll} & 1 & 2 & 3 & 4 \\ \text { Moral judgment } & & & & \\ \text { 1. Accepted interventions } & - & & & \\ \text { 2. Moral acceptability } & .56^{* * *} & - & & \\ \text { Affect } & & & & \\ \text { 3. Valence } & .18^{* *} & .28^{* * *} & - & \\ \text { 4. Arousal } & .07 & .10 & -.52^{* * *} & -\end{array}$

${ }^{*} p<.05 .{ }^{* *} p<.01 .{ }^{* *} p<.001$.

found no significant interactions between age group and these categories.

We first computed partial correlations, controlling for significant sociodemographic differences (Table 3). More negative affect (indicated by lower valence scores) was related to both moral judgment measures, including (a) accepting fewer proposed actions and (b) rating actions as less morally acceptable. Zero-order correlations were similar to partialed equivalents (Table S4). Subsequently, two models examined whether relationships between age group and each of the moral judgment measures were mediated by age-related variations in affect measures. This line of inquiry followed the suggested directionality from affect to moral judgment (Greene et al., 2001; Koenigs et al., 2007). In each model, age group ( 0 = younger, 1 = older) was the predictor, with affective valence and arousal included as mediators. Models controlled for significant sociodemographic differences between age groups. We used version 2.13 of PROCESS (Hayes, 2013) and generated 95\% confidence intervals for indirect effects using 5,000 bootstrap samples. As noted by Hayes (2013), when bootstrap confidence intervals do not contain zero, there is clear evidence that the indirect effect is significant.

\subsection{1 | Accepted interventions}

Older adults accepted fewer interventions and exhibited more negative affect (seen in lower valence) as compared with younger adults, corresponding with ANCOVA results (see Figure 2). ${ }^{2}$ More negative affect, in turn, predicted fewer accepted interventions. The indirect effect of age group on accepted interventions via valence was -.77 $(95 \% \mathrm{Cl}[-1.60,-.27])^{3}$ Thus, older adults' stronger negative affect mediated the link between older age and fewer accepted interventions. Coefficients for sociodemographic covariates indicated significant predictive value for being political right leaning $(B=-2.34$, $p=.041)$ but not for being university educated $(B=-.28, p=.737)$ or ethnicity $(B=-1.34, p=.144)$.

\subsection{2 | Moral acceptability judgments}

Older adults also rated interventions as less acceptable. More negative affect (seen in lower valence) was associated with lower acceptability judgments (Figure 3). The indirect effect of age group

${ }^{2}$ Unstandardized coefficients are presented. Standardized coefficients are available in Supporting Information (see Figures S1 and S2).

${ }^{3}$ All results held when participants who failed an attention check (Maniaci \& Rogge, 2014; $N=29$ ) were removed from analyses.

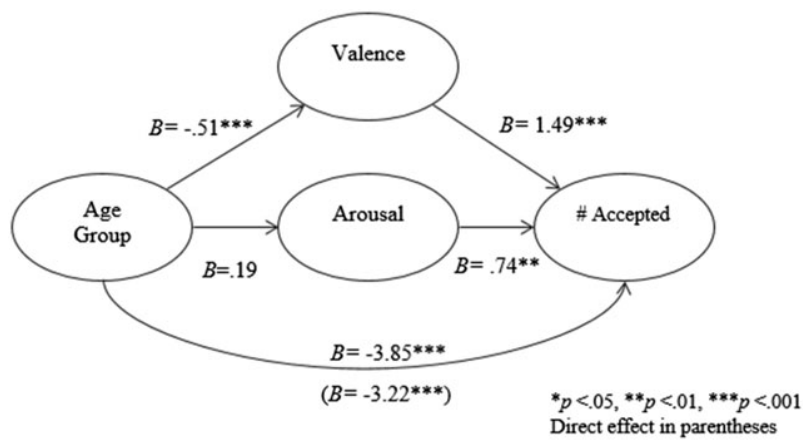

FIGURE 2 Mediation of age effect by negative affect (valence) on moral actions accepted in Experiment 1

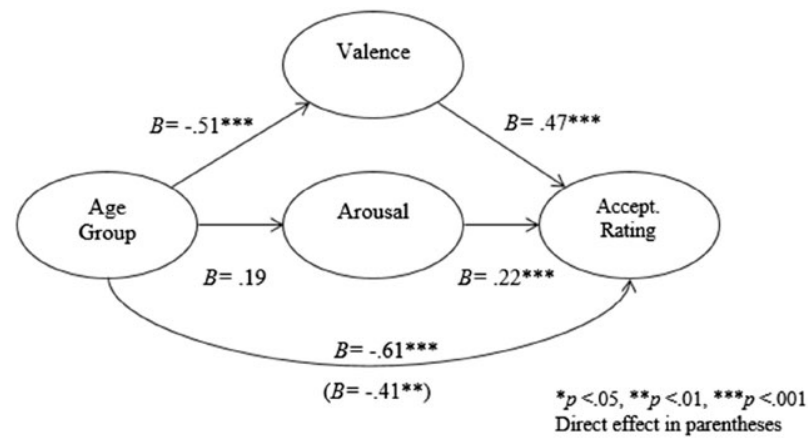

FIGURE 3 Mediation of age effect by negative affect (valence) on moral acceptability judgments in Experiment 1

via valence was $-.24(95 \% \mathrm{Cl}[-.42,-.12])$, suggesting that the relationship between older age and lower moral acceptability judgments was also mediated by older adults' stronger negative affect. Coefficients for sociodemographic covariates indicated significant predictive value for being university educated $(B=.37, p=.044)$ but not for being political right leaning $(B=-.21, p=.282)$ or ethnicity $(B=.05, p=.825)$.

\section{8 | DISCUSSION}

Experiment 1 indicated that older adults made more deontological moral judgments than younger adults. Specifically, older adults accepted fewer interventions and rated them as less morally acceptable. Older adults also reported more negative affect about moral judgments than did younger adults, which accounted for older adults' greater propensity toward deontological moral judgments.

To our knowledge, this is the first report that affective valence mediates age differences in moral judgment. However, other factors could also account for older adults' tendency toward more deontological judgments. For example, older adults may have deficits in fluid cognitive ability (e.g., Hess, 2014; Salthouse, 2004), or lack motivation to deliberate (measured as need for cognition; Bruine de Bruin, McNair, Taylor, Summers, \& Strough, 2015). Older adults also tend to ruminate less (Sütterlin, Paap, Babic, Kübler, \& Vögele, 2012), which can explain why they are better able than younger adults to cut their losses when making decisions involving "sunk costs" (Bruine de Bruin, Strough, \& Parker, 2014). Older adults may also exhibit more morally idealistic beliefs, reflecting greater concern for deontological principles 
(Carlos et al., 2012; Rawwas \& Singhapakdi, 1998). Finally, older adults may use a less "rational" style of decision making (Finucane et al., 2002). Because each of these individual-differences factors may lead older adults to make more deontological moral judgments, we assessed them in Experiment 2.

Additionally, it is possible that Experiment 1's findings were limited to moral dilemmas involving death. Gold et al. (2013) note that, in terms of emotional severity, "death would be at the extreme end of the spectrum, and extreme cases may be treated very differently from intermediate ones" (p. 217). Experiment 2 therefore included moral dilemmas involving less extreme forms of trauma, such as loss of privacy or control or material loss.

\section{9 | EXPERIMENT 2}

Experiment 2 tested the same three research questions as Experiment 1. It involved more diverse moral dilemma scenarios that did not exclusively entail the risk of death. It also included individual-differences measures potentially relevant to age differences in moral judgment.

\section{0 | METHOD}

\section{1 | Participants}

We recruited the same age groups as in Experiment 1, from among $U$. S. residents on Amazon's Mechanical Turk, including 136 older adults (55-75 years, $\left.M_{\text {age }}=60.5, S D=4.2\right)$ and 150 younger adults (1825 years, $M_{\text {age }}=22.9, S D=1.8$ ). The older group comprised $60 \%$ females, $60 \%$ had university degrees and $21 \%$ were non-White. The younger group included $47 \%$ females, $43 \%$ had university degrees and $31 \%$ were non-White. Chi-square tests indicated significant age group differences in gender, $\chi^{2}(1, N=286)=4.76, p=.040$; having a university degree, $\chi^{2}(1, N=286)=8.14, p=.013$, and being religious, $\chi^{2}(1, N=286)=24.70, p<.001$. A chi-square test indicated that age group was also significantly associated with political attitude (left, center, and right): $\chi^{2}(2, N=286)=18.73, p=.001$. Post-hoc tests indicated significant differences in the number of older adults $(N=51)$ identifying as political right leaning compared with younger adults $(N=23): t(284)=4.40, p<.001$. There was also a significant difference in the number of older adults identifying as political left leaning $(N=62)$ compared with younger adults $(N=87): t(284)=2.81$, $p<.04$. All analyses included dummy variables to control for significant sociodemographic factors (gender: $0=$ male, 1 = female; university degree: $0=$ no, 1 = yes; religious: $0=$ no, $1=$ yes; politically right: $0=$ no, 1 = yes; politically left: $0=$ no, $1=$ yes). Participant compensation was the same as in Experiment 1.

\section{2 | Materials}

\subsection{1 | Moral dilemmas}

Participants viewed eight scenarios, including four scenarios from Experiment 1 that yielded the largest age-group differences in judgments (Table S1). Three additional dilemmas (from Gold et al., 2013) did not involve death but rather financial loss (gameshow), material loss (rucksack), or embarrassment (sauna). The final nondeath scenario from Waldmann and Dieterich (2007) involved physical health (virus). Full texts for all scenarios are presented in Supporting Information. The order of presentation of scenarios was randomized across participants.

\subsection{2 | Moral judgment}

These measures were the same as in Experiment 1. For accepted actions, Cronbach's $a=.65$ across death scenarios and .44 across nondeath scenarios. For average acceptability ratings, Cronbach's $a=.86$ across death scenarios and .62 across nondeath scenarios.

\subsection{3 | Affect}

As in Experiment 1, participants indicated their affective valence and arousal. For death scenarios, Cronbach's $a=.87$ for both valence and arousal ratings. For nondeath scenarios, Cronbach's $a=.70$ for valence ratings and .81 for arousal ratings.

\section{3 | Individual-differences measures}

\subsection{1 | Numeracy}

We used the four-item Berlin Numeracy test (Cokely, Galesic, Schulz, Ghazal, \& Garcia-Retamero, 2012) as a proxy for general cognitive ability (Peters, 2012). Numeracy decreases with age (Salthouse, 2012) and is associated with deep elaborative processing of information (Cokely \& Kelley, 2009) as well as less reliance on irrelevant affective cues when reasoning (Peters et al., 2006). Scores could range from 0 to 4 , reflecting correctly solved items (Cronbach's $a=.84)$.

\subsection{2 | Need for cognition}

An 18-item scale (Cacioppo, Petty, \& Kao, 1984) assessed motivation to engage in deliberation (e.g., "Thinking is not my idea of fun"). Responses ranged from 1 (extremely uncharacteristic of me) to 5 (extremely characteristic of me). Higher numbers represented more need for cognition. Need for cognition mediates age differences in numeracy performance (Bruine de Bruin et al., 2015). Cronbach's a was .93.

\subsection{3 | Rumination}

Eight items from the disengagement versus preoccupation subscale of the Action Control Scale (Diefendorff, Hall, Lord, \& Strean, 2000) assessed ruminative thoughts. This subscale has been identified as relevant for understanding age differences in responses to adverse events (Bruine de Bruin et al., 2014; Bruine de Bruin et al., In press). Participants were asked to imagine how they might feel after having made a decision in the scenarios they read and rated several statements for accuracy. An example item asked "When I'm in a competition and lose every time: (a) I can soon put losing out of my mind; (b) The thought that I lost keeps running through my mind."). Ratings ranged from 1 (definitely false) to 5 (definitely true). Higher scores indicated more ruminative thoughts (Cronbach's $a=.84)$. 


\subsection{4 | Moral idealism}

The 10-item moral idealism subscale of Forsyth's (1980) ethics position questionnaire measured participants' deontological moral principles (e.g., "If an action could harm an innocent other, then it should not be done"). Items ranged from 1 (completely disagree) to 9 (completely agree). Higher numbers indicated higher moral idealism (Cronbach's $a=.90$ ). Rawwas and Singhapakdi (1998) observed significantly greater moral idealism in adults ( $M_{\text {age }}=56$ years) compared with a teenage group ( $M_{\text {age }}=19$ years), suggesting this is a characteristic that strengthens with age.

\subsection{5 | Decision-making style}

Given the deliberative/affective distinction in moral judgments (e.g., Greene et al., 2008), we assessed preferences for deliberative and affective decision making, using the rational (5 items, e.g., "My decision making requires careful thought", Cronbach's $\alpha=.80$ ) and intuitive subscales (5 items, e.g., "I generally make decisions that feel right to me", Cronbach's $\alpha=.85$ ) of Scott and Bruce's (1995) decision-making styles battery. Responses ranged from 1 (strongly disagree) to 5 (strongly agree), with higher numbers indicating stronger preferences for the decision-making style.

\section{4 | Procedure}

The procedure in Experiment 2 was identical to that used in Experiment 1, with the exception that individual differences were assessed following the completion of the moral dilemmas.

\section{1 | RESULTS}

\section{1 | Analysis plan}

A 2 (older vs. younger age group) $\times 2$ (death vs. nondeath scenario type) ANCOVA was conducted for moral judgment and affective measures, with sociodemographic covariates (gender, education, religious, politically left, and politically right). To answer Research
Question 1, we examined ANCOVAs for the two moral judgment measures. To answer Research Question 2, we examined ANCOVAs for the two affect measures. We also conducted ANCOVAs on each individual-differences measure, to examine age differences for each, while including the same sociodemographic controls. Table 4 presents descriptive statistics concerning these ANCOVAs. To answer Research Question 3, we performed mediational analyses that examined whether any relationships between age group and moral judgment measures were statistically explained by affect measures while also accounting for individual differences.

\subsection{Do older and younger adults differ in their propensity toward deontological versus utilitarian moral judgments?}

\subsection{1 | Accepted interventions}

A significant main effect of age group, $F(1,279)=7.94, p=.005$, $\eta_{\mathrm{p}}{ }^{2}=.03$, suggested that older adults accepted significantly fewer interventions (Table 4). All remaining tests yielded $F<.49, p>.48$ (Table S5).

\subsection{2 | Moral acceptability judgments}

There was a main effect of scenario type, $F(1,279)=35.62, p=.006$, $\eta_{p}{ }^{2}=.11$, whereby acceptability ratings were significantly lower for death dilemmas $(M=3.55, S D=1.58)$ compared with nondeath dilemmas $(M=4.64, S D=1.19)$. All remaining effects yielded $F<1.17, p>.28$ (Table S5).

\section{3 | Do older and younger adults differ in their affective reactions when making moral judgments?}

\subsection{1 | Valence}

There was a main effect of age group, $F(1,279)=4.24, p=.038$, $\eta_{\mathrm{p}}{ }^{2}=.02$, with older adults giving significantly lower ratings (i.e., more negative affect) compared with younger adults (Table 4). A main effect of scenario type, $F(1,279)=47.83, p<.001, \eta_{p}{ }^{2}=.15$, indicated more negative affect for dilemmas involving death $(M=3.15, S D=1.71)$

TABLE 4 Means (SDs) for measures by type of moral dilemma scenario and age group in Experiment 2

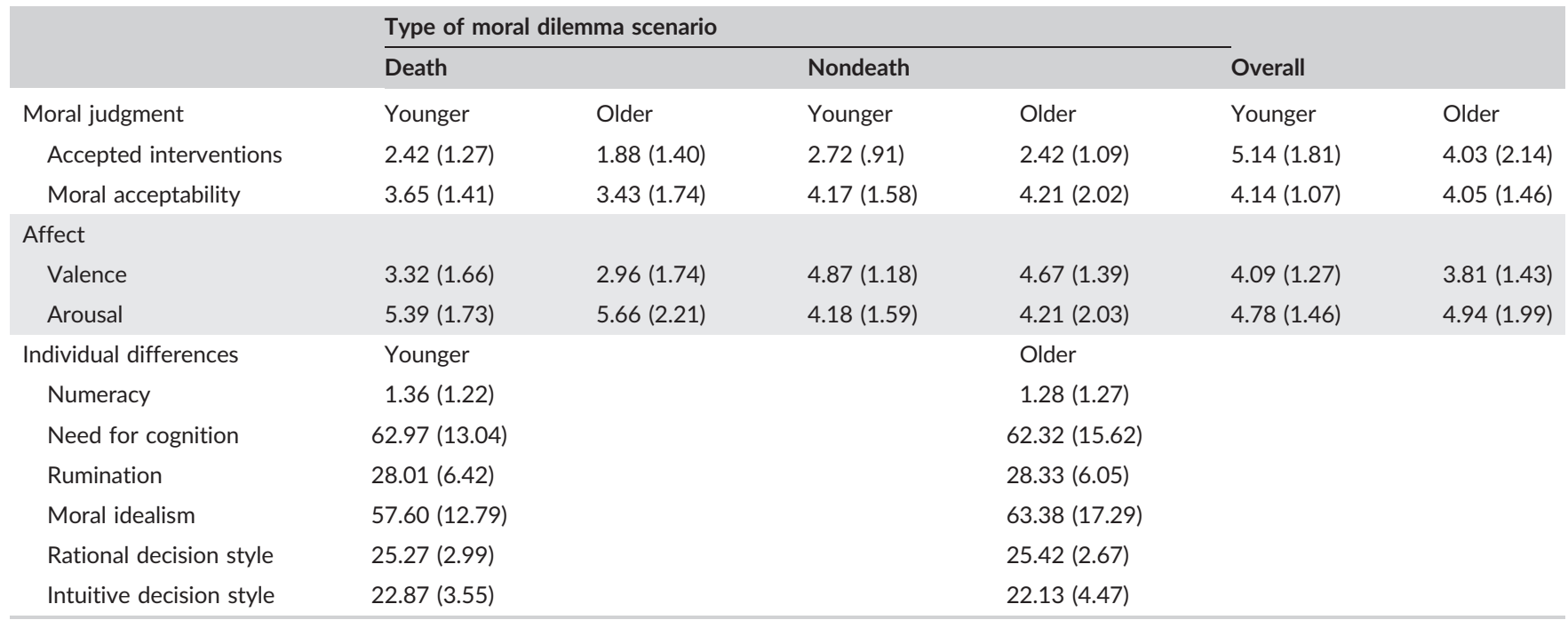


TABLE 5 Partial correlations between measures of moral judgments, affect, and individual differences in Experiment 2

\begin{tabular}{|c|c|c|c|c|c|c|c|c|c|c|}
\hline & 1 & 2 & 3 & 4 & 5 & 6 & 7 & 8 & 9 & 10 \\
\hline \multicolumn{11}{|l|}{ Moral judgment } \\
\hline 1. Accepted interventions & - & & & & & & & & & \\
\hline \multicolumn{11}{|l|}{ Affect } \\
\hline 3. Valence & $.23^{* * *}$ & $.49^{* * *}$ & - & & & & & & & \\
\hline 5. Need for cognition & -.12 & .01 & -.1 & .03 & - & & & & & \\
\hline 6. Rumination & $-.16^{* *}$ & $-.25^{* * *}$ & $-.37^{* * *}$ & .07 & -.05 & - & & & & \\
\hline 7. Numeracy & -.09 & -.01 & $-.16^{*}$ & $-.14^{*}$ & $.19^{* *}$ & .03 & - & & & \\
\hline 8. Rational decision style & -.03 & -.07 & $-.17^{* *}$ & $.14^{*}$ & $.17^{* *}$ & $.12^{*}$ & .05 & - & & \\
\hline
\end{tabular}

${ }^{*} p<.05 .{ }^{* *} p<.01 .{ }^{* * *} p<.001$.

compared with nondeath dilemmas ( $M=4.78, S D=1.28)$. There was no significant interaction between age group and dilemma type, $F(1$, 279) $=1.45, p=.234, \eta_{p}^{2}=.01$.

\subsection{2 | Arousal}

There was a main effect of scenario type, $F(1,279)=24.21, p<.001$, $\eta_{\mathrm{p}}{ }^{2}=.08$, with death dilemmas yielding significantly higher arousal ratings than nondeath dilemmas (Table 4). All remaining effects yielded $F<2.81, p>.11$ (Table S6).

\subsection{3 | Individual-difference measures}

Age group differences were found in moral idealism, $F(1,279)=9.19$, $p=.018, \eta_{p}{ }^{2}=.03$, with older adults $(M=63.40, S D=17.29)$ reporting more morally idealistic views compared with younger adults $(M=57.61, S D=12.78)$. A significant age group difference also emerged for intuitive decision making, $F(1,279)=6.17, p=.031$, $\eta_{\mathrm{p}}{ }^{2}=.02$, with older adults $(M=15.23, S D=10.29)$ scoring higher than younger adults $(M=13.99, S D=9.58)$. There were no other significant age differences in individual-differences measures (all $p>.07)$.

\section{4 | Are any age differences in moral judgments mediated by age differences in affective reactions?}

Table 5 presents partial correlations (controlling for sociodemographic differences) that echo those for Experiment 1. Negative valence was related to accepting fewer interventions and rating such interventions as less morally acceptable. Accepting more interventions was negatively related with rumination and moral idealism and positively related with intuitive decision-making styles. Zero-order correlations were similar to partialed equivalents (Table S7).

As in Experiment 1, we collapsed across scenarios when conducting mediation analyses, because there were no interactions of scenario type with age group. As ANCOVAs indicated age differences only for accepted interventions, we confined our mediation analyses to this dependent variable. The model was the same as in

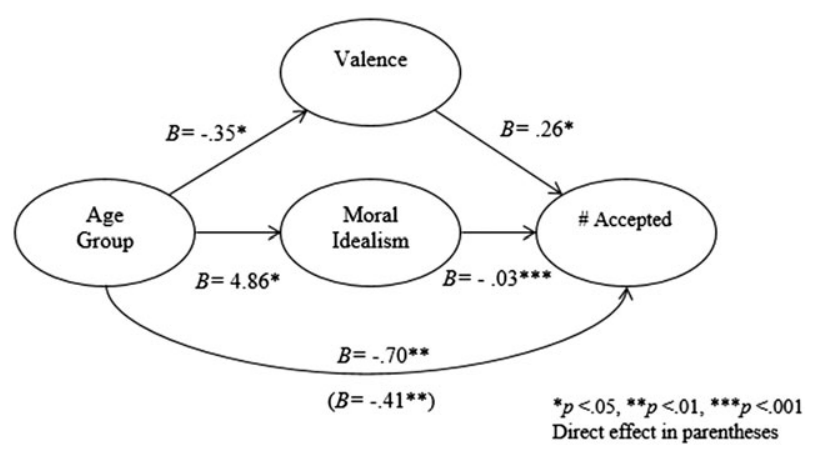

FIGURE 4 Mediation of age effect by negative affect (valence) and moral idealism on moral actions accepted in Experiment 2

Experiment 1, with the exception that all individual differences measures from Experiment 2 were entered as mediators.

Age group predicted both the number of accepted interventions and valence, with older adults accepting fewer interventions and exhibiting more negative affect, in line with ANCOVA results (see Figure 4. Unstandardized coefficients are presented. Standardized coefficients are available in Supporting Information see Figure S3). Older age predicted being more morally idealistic and a more intuitive decision maker. As in Experiment 1, negative affect was associated with fewer choices to intervene. Additionally, higher moral idealism also predicted fewer interventions. We again assessed mediation by generating $95 \%$ confidence intervals for indirect effects using 5,000 bootstrap samples. There were indirect effects of age group on accepted actions via affective valence, -.09 (95\% Cl $[-.26,-.03])$, and via moral idealism, $-.12(95 \% \mathrm{Cl}$ $[-.29,-.03]) .{ }^{4}$ No further factors yielded significant indirect pathways between age group and accepted interventions. Coefficients for the sociodemographic covariates in the model indicated significant predictive value for gender $(B=-.79, p=.006)$ but not for

${ }^{4} \mathrm{All}$ but one of the reported significant findings (mediation by valence) remained after removing 42 respondents who failed an attention check. Removing these participants likely reduced the statistical power to detect this effect, which was small for the full sample. 
being religious ( $B=-.14, p=.942$ ), being political right leaning $(B=-.18, p=.674)$ or left leaning $(B=-.28, p=.344)$, or being university educated $(B=.04, p=.861)$.

\section{2 | DISCUSSION}

Like Experiment 1, Experiment 2 indicated that older adults were more morally deontological than younger adults. Older adults again accepted fewer interventions. The trend for moral acceptability judgments also followed that reported in Experiment 1, where older adults gave lower acceptability ratings, although differences in Experiment 2 were not significant. In line with Experiment 1, we also found that older adults experienced more negative affect when making moral judgments, and that such affective differences mediated the link between age and accepted interventions. It should be noted, however, that the mediating effect of negative affect in Experiment 2 was weaker than in Experiment 1. Additionally, in Experiment 2, we found that age differences in moral judgments are also due to older adults holding more morally idealistic principles. Results held when controlling for a range of relevant individual-difference measures, as well as sociodemographic factors that varied with age.

Interestingly, we found no significant age differences in deliberative capacities such as numeracy, rational decision style, or need for cognition. Possibly, our older respondents were of above-average ability, with $60 \%$ reporting university degrees (compared with U.S. national average of 45\%; Ryan \& Bauman, 2016). Additionally, the Berlin Numeracy Test in particular tends to yield positively skewed distributions in Mechanical Turk samples (e.g., Cokely et al., 2012). Indeed, $80 \%$ of our sample were unable to answer more than $50 \%$ of the items correctly, which may have tempered our ability to detect age differences in numeracy. Although this leaves us unable to determine to what extent such deliberative factors may contribute to age differences in moral judgments, our findings nonetheless shed light on the nuances of why older adults might act more deontologically.

Finally, the absence of interactions between age and dilemma type (death vs. nondeath) suggests that age-related differences in moral judgment also hold for less extreme forms of trauma, which produce less negative affective reactions. This could suggest that both types of scenarios were sufficiently distressing so as to trigger deontological behavior. One interpretation of this and related findings by Gold et al. (2013) could be that the deontological influences of negative affect and moral idealism are triggered by the idea of harm itself, rather than by the specific form or severity of harm. However, the finding that the mediating effect of negative affect was weaker in Experiment 2 (vs. Experiment 1) suggests that the size of this effect may depend to some extent on scenario extremity. Future work could investigate this issue.

\section{3 | GENERAL DISCUSSION}

Taking cue from moral judgment research indicating associations between affective processing and deontological moral judgments (Greene et al., 2001, 2004) and from lifespan developmental research observing greater reliance on affect in the decision making of older adults (e.g., Carstensen, 2006), we investigated age differences in moral judgments and their underlying affective mechanisms. In two experiments, older adults made more deontological judgments than younger adults, which was accounted for by older adults' more negative affective reactions. In Experiment 2, the link between age and moral judgments was also accounted for by older adults' more morally idealistic principles.

\section{1 | Increased deontological judgments in older age due to affective reactions}

Deontological moral judgments tend to be driven by negative affect (Greene et al., 2001, 2004, 2008), whereas positive affect can instead lead to more utilitarian judgments (Valdesolo \& DeSteno, 2006). Across two experiments, we observed that older adults' increased propensity for deontological moral judgments could be statistically explained by their more negative affective reactions. Affective factors may play a larger role in both deontological and utilitarian moral judgments than previously considered (Conway \& Gawronski, 2013; Duke \& Bègue, 2015; Kahane et al., 2015).

Our finding that affect is relevant for understanding age differences in moral judgment dovetails with lifespan developmental studies that highlight older adults' increased reliance on affect (e.g., Mikels et al., 2005; Wood et al., 2005). Such research has also shown that older adults are more likely to act in situations involving sunk cost decisions (e.g., Bruine de Bruin et al., 2014; Bruine de Bruin, Parker, \& Fischhoff, 2012). This implies that it is unlikely that older adults' increased propensity for deontological judgments merely reflects a general tendency toward inaction.

The psychological aging literature also suggests older adults experience a "positivity effect" (e.g., Carstensen, 2006) and exhibit less neural reactivity to negative stimuli (Wood \& Kisley, 2006). Our findings indicate that moral judgments may be a special case of especially adverse negative stimuli, however, where older adults experience greater responsivity (Charles, 2010). As moral dilemmas are designed to evoke strong negative affect, we assume that such dilemmas trigger an affect heuristic (Slovic et al., 2002) that influences subsequent judgments. Other research has shown that older adults, when faced with more negative emotional stimuli, engage more automatic cognitive processes (Dolcos, Katsumi, \& Dixon, 2014). Our findings demonstrate that, in the context of moral judgments, older adults' more negative affective reactions subsequently yield more deontological moral judgments (Greene et al., 2001, 2004).

Relatedly, Hess et al. (2000) report that older adults struggle to disregard affective cues when making judgments. For moral judgments, then, older adults' greater negative affect could drive them toward deontological responses. It may be that older adults choose a deontological course of action (i.e., not intervening) as a means of avoiding further negative feelings associated with sacrificing an individual by intervening (e.g., Lotto et al., 2013). Isaacowitz, Wadlinger, Goren, and Wilson (2006) have indicated that older adults tend to distinctly avoid negative stimuli if they can. Moral dilemmas, however, generally task people with choosing between two upsetting courses of action. In such a context, if older adults' behaviors are 
motivated toward maximizing positive affect (Carstensen, 2006), then a deontological response may be their best option.

An interesting question that remains is what underpins the more negative reactions experienced by older adults. One possibility concerns how people frame the interventions. In a trolley dilemma, interventions could be framed as a gain of, for example, five lives that would otherwise be lost, or as a loss of one life. Older adults prefer to avoid losses more than do younger adults (Depping \& Freund, 2011). Older adults' more saliently negative affective reactions to moral choices may reinforce this preference. Another interesting question relates to the robustness of the mediating role of affective reactions. As noted earlier, this mediating effect was weaker in Experiment 2, which included moral dilemmas that involved potential harms, albeit not always as aversive as the risk of death. Future research could examine age-related differences in moral judgments and affective reactions in response to scenarios that differ in context and aversiveness.

\section{2 | Increased deontological judgments in older age due to moral idealism}

Our findings also revealed that that older adults' moral principles were more strongly characterized by morally idealistic thinking (see Carlos et al., 2012; Hannikainen, Machery, \& Cushman, 2018; Rawwas \& Singhapakdi, 1998), which in turn also accounted for age differences in moral judgment. An idealistic perspective places greater weight on strict adherence to societally defined codes (e.g., "If an action could harm an innocent then it should not be done," Forsyth, 1980). In such light, older adults' relative focus may be on the individual who will be harmed, rather than on the aggregate benefit of intervening. Older adults may be less willing to contravene these stronger idealistic beliefs, which manifests as a deontological decision to not intervene.

Upholding the authority of law represents a further cornerstone of moral idealism. Ma (1985) reports that older adults are less willing to break the law to benefit strangers than they are to benefit loved ones. Although, in our study, we instructed participants to consider that there would be no legal consequences for proposed interventions, older adults may still have been somewhat reluctant to break the law to benefit the strangers described in our scenarios. However, the question remains as to whether any particular facet of older adults' moral idealistic principles exerted greater influence on their decisions to behave deontologically.

These principles concerning harm and authority make up two out of five of proposed intuitive moral foundations in Graham et al.'s (2013) moral foundations theory. However, it has yet to be established whether these foundations vary with age. Assessing how older and younger adults differ in moral foundations concerning harm and authority could further identify the specific idealistic moral beliefs that may drive younger and older adults to differ in their moral decisions.

\section{4 | LIMITATIONS AND FUTURE RESEARCH}

Like any study, ours is subject to limitations that might be addressed by future research. First, given our cross-sectional design, it is possible that the age differences reported may reflect a cohort effect driven by generational differences (see Hannikainen et al., 2018). Although a longitudinal study of moral reasoning would of course be ideal, experimental priming manipulations could also offer further substantiations of the current findings. For example, evidence suggests that younger adults can be primed to respond like older adults through manipulating time horizons (Strough, Schlosnagle, Karns, Lemaster, \& Pichayayothin, 2014).

Second, owing to general limitations of Mechanical Turk samples (Ipeirotis, 2010), our older groups reported higher levels of university level education compared with the U.S. population (Ryan \& Bauman, 2016). Yet our finding that older adults still made predominantly affect-based moral judgments invites the contention that such findings may be stronger in more general older samples, where deliberative capacities may be more heterogenous. Our study may also have been limited in operationalizing deliberative reasoning, where we used numeracy as a proxy of cognitive ability. We thus encourage future research to determine the robustness of our findings using more varied samples of older adults and employing a different measures of cognitive ability such as working memory and processing speed (e.g., Del Missier et al., 2017) and more outright measure of deliberation such as reaction times (see Ghazal, Cokely, \& Garcia-Retamero, 2014).

Finally, follow-up work should also explore whether younger and older adults experience different discrete emotions when faced with moral dilemmas. Although disgust is emotion related specifically to deontological moral judgments (e.g., Ugazio, Lamm, \& Singer, 2012), there is also evidence that older adults experience less disgust (Kunzmann, Kupperbusch, \& Levenson, 2005) but more sadness (Kunzmann \& Grühn, 2005). More nuanced assessments of both deliberation and emotional responses would allow building a more comprehensive model of the factors that can account for age differences in moral judgments, beyond the ones documented in the current work.

\section{ACKNOWLEDGEMENTS}

We gratefully acknowledge support and funding received for this research from The Leverhulme Trust (Early Career Fellowship, ECF2015-067, PI: McNair) and the European Union Seventh Framework Programme (Grant FP7-PEOPLE-2013-CIG-618522, PI: Bruine de Bruin). We thank Fabio Del Missier, JoNell Strough, and Andrew Parker for their constructive comments.

\section{ORCID}

Simon McNair (1D) http://orcid.org/0000-0003-3111-234X

Wändi Bruine de Bruin (D) http://orcid.org/0000-0002-1601-789X

\section{REFERENCES}

Amieva, H., Phillips, L., \& Della Sala, S. (2003). Behavioral dysexecutive symptoms in normal aging. Brain and Cognition, 53(2), 129-132.

Arnett, J. J. (2007). Emerging adulthood: What is it, and what is it good for? Child Development Perspectives, 1(2), 68-73.

Baltes, P. B., \& Smith, J. (2003). New frontiers in the future of aging: From successful aging of the young old to the dilemmas of the fourth age. Gerontology, 49(2), 123-135. 
Bradley, M. M., \& Lang, P. J. (1994). Measuring emotion: The self-assessment manikin and the semantic differential. Journal of Behavior Therapy and Experimental Psychiatry, 25(1), 49-59.

Bruine de Bruin, W., McNair, S. J., Taylor, A. L., Summers, B., \& Strough, J. (2015). "Thinking about numbers is not my idea of fun": Need for cognition mediates age differences in numeracy performance. Medical Decision Making, 35(1), 22-26.

Bruine de Bruin, W., Parker, A. M., \& Fischhoff, B. (2012). Explaining adult age differences in decision-making competence. Journal of Behavioral Decision Making, 25(4), 352-360.

Bruine de Bruin, W., Strough, J., \& Parker, A. M. (2014). Getting older isn't all that bad: Better decisions and coping when facing "sunk costs". Psychology and Aging, 29(3), 642-647.

Bruine de Bruin, W., van Putten, M., van Emden, R., \& Strough, J. (In press). Age differences in emotional responses to monetary losses and gains. Psychology and Aging.

Cacioppo, J. T., Petty, R. E., \& Kao, C. F. (1984). The efficient assessment of need for cognition. Journal of Personality Assessment, 48(2), 306-307.

Carlos, J., Alsua, C. J., \& Carneiro, J. (2012). Moral philosophies and ethics across borders : A study of Brazil, Chile, China, Estonia and the United States. Academia Revista Latinoamericana de Administracion, $49,30-44$

Carstensen, L. L. (2006). The influence of a sense of time on human development. Science (New York, N.Y.), 312(5782), 1913-1915.

Carstensen, L. L., \& Mikels, J. A. (2005). At the intersection of emotion and cognition: Aging and the positivity effect. Current Directions in Psychological Science, 14(3), 117-121.

Carstensen, L. L., \& Turk-Charles, S. (1994). The salience of emotion across the adult life span. Psychology and Aging, 9(2), 259-264.

Charles, S. T. (2010). Strength and vulnerability integration (SAVI): A model of emotional well-being across adulthood. Psychological Bulletin, 136(6), 1068-1091.

Choe, S. Y., \& Min, K. (2011). Who makes utilitarian judgments? The influences of emotions on utilitarian judgments. Judgment and Decision Making, 6(7), 580-592.

Cokely, E., Galesic, M., Schulz, E., Ghazal, S., \& Garcia-Retamero, R. (2012). Measuring risk literacy: The Berlin numeracy test. Judgment and Decision Making, 7(1), 25-47.

Cokely, E. T., \& Kelley, C. M. (2009). Cognitive abilities and superior decision making under risk: A protocol analysis and process model evaluation. Judgment and Decision Making, 4(1), 20-33.

Conway, P., \& Gawronski, B. (2013). Deontological and utilitarian inclinations in moral decision making: A process dissociation approach Journal of Personality and Social Psychology, 104(2), 216-235.

Cushman, F., Young, L., \& Hauser, M. (2006). The role of conscious reasoning and intuition in moral judgment: Testing three principles of harm. Psychological Science, 17(12), 1082-1089.

de la Vi a, L., Garcia-Burgos, D., Okan, Y., Cándido, A., \& González, F. (2015). Disentangling the effect of valence and arousal on judgments concerning moral transgressions. The Spanish Journal of Psychology, 18, 1-9.

Del Missier, F., Hansson, P., Parker, A. M., Bruine de Bruin, W., Nilsson, L. G., \& Mäntylä, T. (2017). Unraveling the aging skein: Disentangling the effects of sensory and cognitive predictors on decision making. Journal of Behavioral Decision Making, 30(1), 123-139.

Depping, M. K., \& Freund, A. M. (2011). Normal aging and decision making: The role of motivation. Human Development, 54(6), 349-367.

Diefendorff, J. M., Hall, R. J., Lord, R. G., \& Strean, M. L. (2000). Actionstate orientation: construct validity of a revised measure and its relationship to work-related variables. Journal of Applied Psychology, 85(2), 250-263.

Duke, A. A., \& Bègue, L. (2015). The drunk utilitarian: Blood alcohol concentration predicts utilitarian responses in moral dilemmas. Cognition, 134, 121-127.
Finucane, M. L., Slovic, P., Hibbard, J. H., Peters, E., Mertz, C. K., \& MacGregor, D. G. (2002). Aging and decision-making competence: An analysis of comprehension and consistency skills in older versus younger adults considering health-plan options. Journal of Behavioral Decision Making, 15(2), 141-164.

Foot, P. (1967). The problem of abortion and the doctrine of the double effect. Oxford Review, 5, 5-15.

Forsyth, D. R. (1980). A taxonomy of ethical ideologies. Journal of Personality and Social Psychology, 39(1), 175-184.

Fung, H. H., \& Carstensen, L. L. (2003). Sending memorable messages to the old: Age differences in preferences and memory for advertisements. Journal of Personality and Social Ssychology, 85(1), 163-178.

Ghazal, S., Cokely, E. T., \& Garcia-Retamero, R. (2014). Predicting biases in very highly educated samples: Numeracy and metacognition. Judgment and Decision Making, 9(1), 15.

Gold, N., Pulford, B. D., \& Colman, A. M. (2013). Your money or your life: Comparing judgements in trolley problems involving economic and emotional harms, injury and death. Economics and Philosophy, 29(2), 213-233.

Graham, J., Haidt, J., Koleva, S., Motyl, M., Iyer, R., Wojcik, S., \& Ditto, P. H. (2013). Moral foundations theory: The pragmatic validity of moral pluralism. In P. Devine, \& A. Plant (Eds.), Advances in experimental social psychology (Vol. 47) (pp. 55-130). San Diego, CA: Academic Press.

Greene, J. D., Morelli, S. A., Lowenberg, K., Nystrom, L. E., \& Cohen, J. D. (2008). Cognitive load selectively interferes with utilitarian moral judgment. Cognition, 107(3), 1144-1154.

Greene, J. D., Nystrom, L. E., Engell, A. D., Darley, J. M., \& Cohen, J. D. (2004). The neural bases of cognitive conflict and control in moral judgment. Neuron, 44, 389-400.

Greene, J. D., Sommerville, R. B., Nystrom, L. E., Darley, J. M., \& Cohen, J. D. (2001). An fMRI investigation of emotional engagement in moral judgment. Science, 293(5537), 2105-2108.

Hannikainen, I. R., Machery, E., \& Cushman, F. A. (2018). Is utilitarian sacrifice becoming more morally permissible? Cognition, 170, 95-101.

Hauser, M., Cushman, F., Young, L., Kang-Xing, J., \& Mikhail, J. (2007). A dissociation between moral judgments and justifications. Mind \& Language, 22(1), 1-21.

Hayes, A. F. (2013). Introduction to mediation, moderation, and conditional process analysis. New York: Guilford Press.

Hess, T. M. (2014). Selective engagement of cognitive resources: Motivational influences on older adults' cognitive functioning. Perspectives on Psychological Science, 9(4), 388-407.

Hess, T. M., Strough, J., \& Lockenhoff, C. E. (Eds.) (2015). Aging and decision making: Empirical and applied perspectives. London, UK: Academic Press.

Hess, T. M., Waters, S. J., \& Bolstad, C. A. (2000). Motivational and cognitive influences on affective priming in adulthood. Journals of Gerontology Series B: Psychological Sciences and Social Sciences, 55(4), P193-P204.

Ipeirotis, P. G. (2010). Analyzing the Amazon Mechanical Turk marketplace. XRDS: Crossroads, the ACM Magazine for Students, 17(2), 16-21.

Isaacowitz, D. M., Toner, K., Goren, D., \& Wilson, H. R. (2008). Looking while unhappy: Mood-congruent gaze in young adults, positive gaze in older adults. Psychological Science, 19(9), 848-853.

Isaacowitz, D. M., Wadlinger, H. A., Goren, D., \& Wilson, H. R. (2006). Selective preference in visual fixation away from negative images in old age? An eye-tracking study. Psychology and Aging, 21(1), 40-48.

Kahane, G., Everett, J. A. C., Earp, B. D., Farias, M., \& Savulescu, J. (2015). "Utilitarian" judgments in sacrificial moral dilemmas do not reflect impartial concern for the greater good. Cognition, 134, 193-209. 
Kensinger, E. A. (2008). Age differences in memory for arousing and nonarousing emotional words. The Journals of Gerontology Series B: Psychological Sciences and Social Sciences, 63(1), 13-18.

Kessler, E. M., \& Staudinger, U. M. (2009). Affective experience in adulthood and old age: The role of affective arousal and perceived affect regulation. Psychology and Aging, 24(2), 349-362.

Koenigs, M., Kruepke, M., Zeier, J., \& Newman, J. P. (2011). Utilitarian moral judgment in psychopathy. Social cognitive and affective neuroscience, $7(6), 708-714$.

Koenigs, M., Young, L., Adolphs, R., Tranel, D., Cushman, F., Hauser, M., \& Damasio, A. (2007). Damage to the prefrontal cortex increases utilitarian moral judgements. Nature, 446, 908-911.

Kovalchik, S., Camerer, C. F., Grether, D. M., Plott, C. R., \& Allman, J. M. (2005). Aging and decision making: A comparison between neurologically healthy elderly and young individuals. Journal of Economic Behavior and Organization, 58(1), 79-94.

Kunzmann, U., \& Grühn, D. (2005). Age differences in emotional reactivity: The sample case of sadness. Psychology and Aging, 20(1), 47-59.

Kunzmann, U., Kupperbusch, C. S., \& Levenson, R. W. (2005). Behavioral inhibition and amplification during emotional arousal: A comparison of two age groups. Psychology and Aging, 20(1), 144-158.

Lachman, M. E. (2004). Development in midlife. Annual Review of Psychology, 55, 305-331.

Leigland, L. A., Schulz, L. E., \& Janowsky, J. S. (2004). Age related changes in emotional memory. Neurobiology of Aging, 25(8), 1117-1124.

Lotto, L., Manfrinati, A., \& Sarlo, M. (2013). A new set of moral dilemmas: Norms for moral acceptability, decision times, and emotional salience. Journal of Behavioral Decision Making, 27(1), 57-65.

Ma, H. K. (1985). Cross-cultural study of the development of law-abiding orientation. Psychological Reports, 57(3), 967-974.

Maniaci, M. R., \& Rogge, R. D. (2014). Caring about carelessness: Participant inattention and its effects on research. Journal of Research in Personality, 48, 61-83.

Mata, R., Josef, A. K., Samanez-Larkin, G. R., \& Hertwig, R. (2011). Age differences in risky choice: A meta-analysis. Annals of the New York Academy of Sciences, 1235(1), 18-29.

Mather, M., \& Carstensen, L. L. (2005). Aging and motivated cognition: The positivity effect in attention and memory. Trends in Cognitive Sciences, 9(10), 496-502.

Mikels, J. A., Larkin, G. R., Reuter-Lorenz, P. A., \& Carstensen, L. L. (2005) Divergent trajectories in the aging mind: Changes in working memory for affective versus visual information with age. Psychology and Aging, 20(4), 542-553.

Moore, A. B., Clark, B. a., \& Kane, M. J. (2008). Who shalt not kill? Individual differences in working memory capacity, executive control, and moral judgment. Psychological Science, 19(6), 549-557.

Myatt, M. (2013). DNA of Fortune 100 CEOS. Retrieved from: http:// www.forbes.com/sites/mikemyatt/2013/08/13/infographic-dna-offortune-100-ceos/

Peters, E. (2012). Beyond comprehension: The role of numeracy in judgments and decisions. Current Directions in Psychological Science, 21(1), 31-35.

Peters, E., \& Bruine de Bruin, W. (2012). Aging and decision skills. Judgment and Decision Making as a Skill: Learning, Development, and Evolution, 5, 113-1139.

Peters, E., Västfjäll, D., Slovic, P., Mertz, C. K., Mazzocco, K., \& Dickert, S. (2006). Numeracy and decision making. Psychological Science, 17(5), 407-413.

Piazza, J., \& Sousa, P. (2014). Religiosity, political orientation, and consequentialist moral thinking. Social Psychological and Personality Science, 5(3), 334-342.

Pratt, M. W., Diessner, R., Pratt, A., Hunsberger, B., \& Pancer, S. M. (1996). Moral and social reasoning and perspective taking in later life: A longitudinal study. Psychology and Aging, 11(1), 66-73.
Rawwas, M. Y. A., \& Singhapakdi, A. (1998). Do consumers' ethical beliefs vary with age? A substantiation of Kohlberg's typology in marketing. Journal of Marketing Theory and Practice, 6(2), 26-38.

Reuter-Lorenz, P. A., \& Sylvester, C. Y. C. (2005). The cognitive neuroscience of working memory and aging. In R. Cabeza, L. Nyberg, \& D. Park (Eds.), Cognitive neuroscience of aging: Linking cognitive and cerebral aging (pp. 186-217). New York: Oxford University Press.

Ryan, C. L., \& Bauman, K. (2016). Educational attainment in the United States: 2015 (United States Census Bureau Publication No. P 20-578). Washington, D.C.: US Government Printing Office.

Salthouse, T. A. (2004). What and when of cognitive aging. Current Directions in Psychological Science, 13(4), 140-144.

Salthouse, T. A. (2012). Consequences of age-related cognitive declines. Annual Review of Psychology, 63, 201-226.

Dolcos, S., Katsumi, Y., \& Dixon, R. A. (2014). The role of arousal in the spontaneous regulation of emotions in healthy aging: A fMRI investigation. Frontiers in Psychology, 5.

Scott, S. G., \& Bruce, R. A. (1995). Decision-making style: The development and assessment of a new measure. Educational and psychological measurement, 55(5), 818-831.

Slovic, P., Finucane, M. L., Peters, E., \& MacGregor, D. G. (2002). Rational actors or rational fools? Implications of the affect heuristic for behavioral economics. In T. Gilovich, D. Griffin, \& D. Kahneman (Eds.), Heuristics and biases: The psychology of intuitive judgment (pp. 397-420). Boston: Cambridge University Press.

Strough, J., Mehta, C. M., McFall, J. P., \& Schuller, K. L. (2008). Are older adults less subject to the sunk-cost fallacy than younger adults? Psychological Science, 19(7), 650-652.

Strough, J., Schlosnagle, L., Karns, T., Lemaster, P., \& Pichayayothin, N. (2014). No time to waste: Restricting life-span temporal horizons decreases the sunk-cost fallacy. Journal of Behavioral Decision Making, 27(1), 78-94.

Suter, R. S., \& Hertwig, R. (2011). Time and moral judgment. Cognition, 119(3), 454-458.

Sütterlin, S., Paap, M. C. S., Babic, S., Kübler, A., \& Vögele, C. (2012). Rumination and age: Some things get better. Journal of Aging Research, 2012, 267-327.

Thomson, J. J. (1985). The trolley problem. Yale Law Journal, 94(6), $1395-1415$.

Torges, C. M., Stewart, A. J., \& Nolen-Hoeksema, S. (2008). Regret resolution, aging, and adapting to loss. Psychology and Aging, 23(1), 169-180.

Ugazio, G., Lamm, C., \& Singer, T. (2012). The role of emotions for moral judgments depends on the type of emotion and moral scenario. Emotion, 12(3), 579-590.

Valdesolo, P., \& DeSteno, D. (2006). Manipulations of emotional context shape moral judgment. Psychological Science, 17(6), 476.

Verhaeghen, P., Marcoen, A., \& Goossens, L. (1993). Facts and fictions about memory and aging: A quantitative integration of research findings. Journal of Gerontology, 48, 157-171.

Waldmann, M. R., \& Dieterich, J. H. (2007). Throwing a bomb on a person versus throwing a person on a bomb: Intervention myopia in moral intuitions. Psychological Science, 18(3), 247-253.

Walker, L. J. (2014). Sex differences in moral reasoning. In W. M. Kurtines, \& J. L. Gewitz (Eds.), Handbook of moral behavior and development (pp. 333-364). New York: Psychology Press.

Wood, S., Busemeyer, J., Koling, A., Cox, C. R., \& Davis, H. (2005). Older adults as adaptive decision makers: Evidence from the lowa gambling task. Psychology and Aging, 20(2), 220-225.

Wood, S., \& Kisley, M. A. (2006). The negativity bias is eliminated in older adults: Age-related reduction in event-related brain potentials associated with evaluative categorization. Psychology and Aging, 21(4), 815-820. 
Simon McNair is a Leverhulme Early Career Research Fellow at Leeds University Business School, University of Leeds, UK. His research interests are in individual differences in judgment and decision making in domains such as consumer behavior, moral judgment, and aging.

Yasmina Okan is a Cancer Research UK Research Fellow and Associate Professor in Behavioral Decision Making at Leeds University Business School, University of Leeds, UK. Her research focuses on designing effective risk communications to support decision making (e.g., graphical displays). She also studies how contextual and emotional factors influence moral judgments.

Constantinos Hadjichristidis is an Associate Professor at the Department of Economics and Management, University of Trento, Italy. His research is generally focused on the interplay of cognitive and affective factors in judgment and decision making. His recent work has studied how foreign language influences moral judgment.
Wändi Bruine de Bruin is Professor of Behavioral Decision Making at Leeds University Business School, University of Leeds, UK. Her research focuses on judgment and decision making, risk perception, and communication, as well as individual differences in decision-making competence

\section{SUPPORTING INFORMATION}

Additional supporting information may be found online in the Supporting Information section at the end of the article.

How to cite this article: McNair S, Okan Y, Hadjichristidis C, Bruine de Bruin, W. Age differences in moral judgment: Older adults are more deontological than younger adults. J Behav Dec Making. 2019;32:47-60. https://doi.org/10.1002/bdm.2086 